\title{
EFEITO DO TEOR DE UMIDADE DO SOLO NA SELETIVIDADE E NA EFICIÊNCIA DE CARFENTRAZONE-ETHYL NO CONTROLE DE PLANTAS DANINHAS NA CULTURA DE SOJA
}

\author{
Erivelton Scherer Roman ${ }^{1}$; Leandro Vargas ${ }^{2}$; Marcelo Carlos Fortes Ribeiro ${ }^{3}$ \\ ${ }^{1}$ Eng.-Agr., Ph. D., Pesquisador da Embrapa Trigo, Caixa Postal 451, CEP 99001-970 Passo Fundo, RS. \\ eroman@cnpt.embrapa.br \\ ${ }^{2}$ Eng.-Agr., D. Sc., Pesquisador da Embrapa Trigo, Caixa Postal 451, CEP 99001-970 Passo Fundo, RS. \\ vargas@cnpt.embrapa.br \\ ${ }^{3}$ Acadêmico da Faculdade de Agronomia e Medicina Veterinária da Universidade de Passo Fundo, estagiário da \\ Embrapa Trigo, Passo Fundo, RS.
}

\section{RESUMO}

O presente trabalho teve por objetivo verificar a influência do teor de umidade do solo e, por inferência, das plantas, na resposta da soja e de Euphorbia heterophylla L. à aplicação de carfentrazone-ethyl aplicado sozinho e em mistura com imazethapyr. O experimento foi conduzido em campo, na área experimental da Embrapa Trigo, no município de Passo Fundo, RS, na safra agrícola 2001/2002. O solo é um Latossolo Vermelho Distrófico típico, de textura média. A cultivar de soja reagente foi a BRS 154. O delineamento experimental foi de experimento em faixas, com quatro repetições. As faixas eram constituídas pela irrigação: sem irrigação e irrigação com $30 \mathrm{~mm}$ de água, através de aspersores, realizada no dia anterior à aplicação dos tratamentos com os herbicidas e pelos dois herbicidas testados: carfentrazone-ethyl, na dose de 10,0 g i.a./ha, isoladamente e em mistura com imazethapyr, na dose de $24,5 \mathrm{~g}$ i.a./ha. Foram incluídas uma testemunha capinada e uma testemunha sem capina. O status hídrico do solo, e das plantas, antes da aplicação dos tratamentos, influenciou o efeito de carfentrazone-ethyl: os sintomas fitotóxicos foram em maior grau quando o produto foi aplicado sobre as plantas de soja que não estavam sob estresse hídrico. O melhor controle de $E$. heterophylla foi obtido pela mistura de carfentrazone-ethyl + imazethapyr, aplicado sobre plantas que não apresentavam estresse hídrico. As plantas de soja recuperaram-se da fitotoxicidade inicial causada pelos tratamentos com carfentrazone-ethyl e não houve efeito sobre a altura final de plantas e nem na produtividade de biomassa e de grãos.

Palavras chave: estresse hídrico, herbicida, eficiência, fitotoxicidade.

\section{ABSTRACT \\ Effect of soil moisture status on carfentrazone-ethyl selectivity and weed control on soybeans}

The effects of soil water and, by inference, the plant water status prior to herbicide treatment, on the response of soybean and Euphorbia heterophylla L. to carfentrazoneethyl applied alone and in mixture with imazethapyr were studied under field conditions. The study was conducted during the 2001/2002 growing season. The experimental design was a split block in strips with four replications. The strips consisted of irrigation (irrigation and no-irrigation) and herbicide. The irrigation consisted of an event of $30 \mathrm{~mm}$ of water 
which was carried-out in the day prior to herbicide application using sprinklers. The herbicides were carfentrazone-ethyl $10,0 \mathrm{~g}$ a. i. ha ${ }^{-1}$, carfentrazone-ethyl $10,0 \mathrm{~g} \mathrm{a}$. i./ha + imazethapyr $24,5 \mathrm{~g}$ a. i./ha. A check and a hoed treatment were included. High moisture status plants (irrigated) were more sensitive to carfentrazone-ethyl applied alone and in mixture with imazethapyr than unirrigated plants. The best $E$. heterophylla control was given by carfentrazone-ethyl $10,0 \mathrm{~g} \mathrm{a}$. i.//ha ${ }^{1}+$ imazethapyr $24,5 \mathrm{~g}$ a. i./ha. Soybean plants recovered from the initial phytotoxicity caused by carfentrazone-ethyl treatments and there was neither effect on the final plant height or biomass and grain yield.

Key words: water stress, herbicide, efficacy, phytotoxicity.

\section{INTRODUÇÃO}

A atividade dos herbicidas está relacionada às condições de ambiente. Danos à cultura causados por herbicidas de ação de contato são associados à condições de elevada umidade e temperatura do ambiente. Essas condições, no entanto, favorecem a eficiência desses compostos no controle de plantas daninhas (Ritter \& Coble, 1981; Jeffcoat et al. 1977; Harrison et al. 1996; Adkins et al. 1998).

Carfentrazone-ethyl é um herbicida, pertencente ao grupo químico das aril triazolinonas, cujo mecanismo de ação é a inibição da enzima protox (Dayan et al. 1997) na biossíntese da clorofila, o que resulta na acumulação de protoporfirina no citosol (Sherman et al. 1991). A protoporfirina está envolvida no mecanismo da formação de "singleto" de oxigênio $\left(\mathrm{O}_{2}\right)$, o qual, por sua vez, causa a destruição da membrana celular, via a sua peroxidação (Devine et al. 1993). Esse herbicida é de ação de contato com pequena ou nenhuma ação residual, sendo rapidamente absorvido pelas folhas (FMC, 2001). Os sintomas, nas folhas de plantas daninhas sensíveis ao produto, aparecem em poucas horas após a sua aplicação são caracterizados por sinais de dessecação, seguidos por necrose e morte da planta dentro de poucos dias. Como a produtividade de matéria seca e econômica depende também da translocação de assimilados das folhas ou de outros órgãos fotossintetizantes (Hay \& Walker, 1992) ela pode ser influenciada pela queima de folhas causadas por herbicidas.

Estudos indicam que a seletividade dos herbicidas aril triazolinonas (carfentrazoneethyl e sulfentrazone) é baseada nas suas taxa de detoxificação pelas plantas (Dayan et al. 1997). A soja e o milho detoxificam esses compostos mais rapidamente que plantas daninhas, indicando que a sua seletividade é, pelo menos parcialmente, explicada pela rapidez dessas reações. No entanto, formas fitotóxicas desses herbicidas foram detectadas nas plantas (Dayan et al. 1997), existindo, portanto, a possibilidade de que outros processos e/ou fatores podem estar envolvidos na proteção contra os efeitos desses produtos.

Por apresentarem modos e mecanismos de ação diferentes, o emprego de misturas em tanque de herbicidas do grupo das aril triazolinonas com os do grupo das imidazolinonas (Rodrigues, 1995), apresentam-se como estratégia para prevenir e/ou manejar a resistência de plantas daninhas a herbicidas na cultura de soja. $O$ uso de misturas de herbicidas com diferentes locais de ação e com diferentes mecanismos de degradação metabólica é também sugerido por Gressel e Segel (1990), para evitar ou retardar o aparecimento do problema. Além disso, essas misturas melhoram o controle de plantas daninhas, pela combinação da ação rápida de contato das aril triazolinonas, dessecando as plantas, com a ação sistêmica das imidazolinonas que pode atingir pontos 
de crescimentos e/ou órgãos subterrâneos.

Euphorbia heterophylla L. é uma importante espécie de planta daninha na cultura de soja (Reunião...). Os danos causados por essa espécie, reduzindo a produtividade e a qualidade de grãos, são consideráveis e variam em função de sua densidade populacional, da época de emergência e das condições do ambiente.

O objetivo do presente trabalho foi verificar a influência do teor de umidade do solo e, por inferência, das plantas, na resposta da soja e de Euphorbia heterophylla L. à aplicação de carfentrazone-ethyl aplicado sozinho e em mistura com imazethapyr.

\section{MATERIAL E MÉTODOS}

O experimento foi conduzido em condições de campo na área experimental da Embrapa Trigo, localizada no município de Passo Fundo RS, na safra agrícola 2001/2002. O solo é de textura média, com $42 \%$ de argila e 4,0\% de matéria orgânica, pertencente à Unidade de Mapeamento Passo Fundo (Latossolo Vermelho distrófico típico). A cultivar de soja foi a BRS 154, semeada na densidade de 14 plantas por metro linear, no espaçamento de 0,45 m entre linhas, em 15/12/2001, em sistema plantio direto. A adubação foi realizada usando-se $250 \mathrm{~kg} / \mathrm{ha}$ de adubo, na fórmula 05-25-25.

O delineamento experimental foi de experimento em faixas, com quatro repetições. As faixas eram constituídas pela irrigação: sem irrigação e irrigação com $30 \mathrm{~mm}$ de água, através de aspersores, realizada no dia anterior à aplicação dos tratamentos com os herbicidas e pelos dois herbicidas testados: carfentrazone-ethyl, na dose de $10,0 \mathrm{~g}$ i.a./ha, isoladamente e em mistura com imazethapyr, na dose de $24,5 \mathrm{~g}$ i.a./ha. Foram incluídas uma testemunha capinada e uma testemunha sem capina.

A aplicação dos herbicidas foi realizada em pós-emergência, usando-se pulverizador costal de precisão, com pressão de trabalho de $15 \mathrm{lb} . p o l^{-2}$ dada por gás carbônico, munido de bicos de jato em forma de leque, tipo 110015 , espaçados $0,5 \mathrm{~m}$ entre si e posicionados à altura de $50 \mathrm{~cm}$ acima das plantas. O volume de calda usado foi de $100 \mathrm{~L} / \mathrm{ha}$. Não foi adicionado qualquer adjuvante à calda de pulverização. Antes da aplicação dos tratamentos com herbicidas, determinou-se o teor de água no solo nas parcelas irrigadas e não irrigadas, usando-se equipamento Trase System $6050 \times 1{ }^{1}$. Esses teores eram de $17 \%$ e de $32 \%$, correspondentes, na curva característica de retenção de água no solo, ao potencial hídrico de $-0,1 \mathrm{MPa}$ (as plantas se encontravam sob estresse hídrico, caracterizado pela presença de plantas com folhas murchas) e de -0,002 MPa (capacidade de campo), respectivamente. Após a aplicação dos herbicidas, ocorreram chuvas a partir de 2 DAT (dias após a aplicação dos tratamentos) e a cultura se desenvolveu normalmente, sem sofrer déficitees hídricos significativos.

No momento da aplicação, o estádio de desenvolvimento de soja era de 2 a 3 trifólios (estádio V3); a planta daninha (Euphorbia heterophylla L.) encontrava-se no estádio de crescimento de 2 a 5 folhas, com densidade populacional de cerca de 400 plantas $/ \mathrm{m}^{2}$. A umidade relativa e a temperatura, do ar, eram $61 \%$ e $27{ }^{\circ} \mathrm{C}$, respectivamente.

A eficiência dos tratamentos no controle de Euphorbia heterophylla L. foi determinada aos 5, 21 e aos 35 DAT, pelo método de avaliação visual, atribuindo-se notas em porcentagem de controle em relação à testemunha. A escala empregada variou entre 0 (sem danos visíveis) e 100 \% (morte total de plantas). Foi constatada a ocorrência de manchas foliares em plantas de E. heterophylla, a partir dos 21 DAT, atribuídas à infecção por Bipolaris sp. 
A avaliação da fitotoxicidade às plantas de soja foi realizada visualmente aos 5 DAT (V3) e aos 21 DAT (V5), e os resultados expressos em porcentagem de danos, tomando como base a redução do crescimento e de matéria seca, a clorose e a queima da parte aérea foliar (Lich et al., 1997) e pela avaliação dos efeitos dos tratamentos na altura de plantas de soja. A altura de plantas foi determinada em 20 plantas por parcela, aos 10 e 21 DAT. A produção de matéria seca, determinada em $1 \mathrm{~m}^{2}$ e o rendimento de grãos de soja, determinado na área útil de $14 \mathrm{~m}^{2}$ em cada unidade experimental e transformados em $\mathrm{kg} / \mathrm{ha}$.

Tabela 1. Tratamentos químicos aplicados em pós-emergência no controle de Euphorbia heterophylla L. Passo Fundo, RS, 2001/2002

\begin{tabular}{lccc}
\hline \multirow{2}{*}{ Nome comercial } & Nome técnico & \multicolumn{2}{c}{ Dose } \\
\cline { 3 - 4 } & - & $\begin{array}{c}\text { Ingrediente ativo } \\
(\mathrm{g} / \mathrm{ha})\end{array}$ & $\begin{array}{c}\text { Produto comercial } \\
\text { (dose/ha) }\end{array}$ \\
\hline $\begin{array}{l}\text { Testemunha } \\
\text { Testemunha capinada }\end{array}$ & - & - & - \\
$\begin{array}{l}\text { Carfentrazone-ethyl } \\
\text { Carfentrazone-ethyl } \\
\text { +imazethapyr }\end{array}$ & Aurora $^{2}$ & - & - \\
\hline
\end{tabular}

${ }^{1}$ Trace System model 6050X1 (Soil Moisture Equipment Corp., Santa Barbara, CA).

${ }^{2}$ Aurora contém $400 \mathrm{~g}$ de carfentrazone-ethyl por litro de produto comercial, na formulação concentrado emulsionável (FMC Química do Brasil Ltda, Campinas, SP).

${ }^{3}$ Dinamaz, contém $700 \mathrm{~g}$ de imazethapyr por $\mathrm{Kg}$ de produto comercial, na formulação grânulos autodispersíveis em água (Cheminova Agro Brasil Ltda, Vila Santa Catarina, SP).

\section{RESULTADOS E DISCUSSÃO}

Devido a ocorrência de interação significativa entre os fatores, para os parâmetros avaliados (fitotoxicidade aos 5 DAT, altura de plantas aos 10 DAT, produção de matéria seca (biomassa) de soja no florescimento, controle da planta daninha aos 5, 21 e 35 DAT (V6) e produtividade de grãos), as interações foram desdobradas e as comparações entre os tratamentos foram realizadas separadamente para cada regime de irrigação (Schabenberger, 2001).

A deficiência hídrica no solo e, por inferência, na planta, influenciou a resposta da cultura ao carfentrazone-ethyl. Os graus de fitotoxicidade na soja foram estatísticamente maiores, aos 5 DAT, nos tratamentos que receberam irrigação, ou seja, quando as plantas de soja não se encontravam sob estresse hídrico $(P=0,0003)$. Assim, as plantas sob irrigação apresentavam $26,6 \%$ a $30 \%$ de área foliar queimada enquanto que nas plantas sob estresse, a queima era de $16 \%$ a $21 \%$ aos 5 DAT, indicando que a soja é mais sensível ao carfentrazone-ethyl quando o produto é aplicado sobre soja sob condições de adequada umidade no solo e, por inferência, com adequado status hídrico na planta (Tabela 2). 
Tabela 2. Queima da área foliar, em \%, causada à soja pelos tratamentos. Passo Fundo, RS, 2001/2002.

\begin{tabular}{lccccc}
\hline \multirow{2}{*}{ Nome técnico } & $\begin{array}{c}\text { Ingrediente } \\
\text { Ativo }\end{array}$ & \multicolumn{2}{c}{5 DAT } & \multicolumn{2}{c}{21 DAT } \\
\cline { 3 - 6 } & $(\mathrm{g} / \mathrm{ha})$ & $\begin{array}{c}\text { Não } \\
\text { Irrigado }\end{array}$ & Irrigado & $\begin{array}{c}\text { Não } \\
\text { Irrigado }\end{array}$ & Irrigado \\
\hline Testemunha & - & $0 \mathrm{c}$ & $0 \mathrm{~b}$ & 0 & 0 \\
Testemunha capinada & - & $0 \mathrm{c}$ & $0 \mathrm{~b}$ & 0 & 0 \\
Carfentrazone-ethyl & 10 & $15 \mathrm{~b}$ & $26,6 \mathrm{a}$ & 0 & 1,7 \\
Carfentrazone-ethyl + & $10+24,5$ & $20 \mathrm{a}$ & $30,0 \mathrm{a}$ & 0 & 1,7 \\
imazethapyr & & 17,0 & 17,6 & & 23,0 \\
C. $\mathrm{V}(\%)$ & & 17,0 &
\end{tabular}

Valores seguidos pela mesma letra, na coluna, não diferem entre si pelo teste de Duncan, ao nível de probabilidade de erro de $5 \%$.

Os sintomas de fitotoxicidade as plantas de soja causadas pelas aplicações dos produtos foram identificadas pelo encrespamento, enrolamento e queima da área foliar como também relatado por Ashton \& Crafts, (1981) e manchas nas folhas expostas aos tratamentos com herbicidas, as quais apresentam coloração vermelho-alaranjada. $O$ coalescimento das manchas e a desidratação levou à necrose dos tecidos. No entanto, os novos brotos não foram afetados, de forma que aos 21 DAT, as plantas de soja haviam se recuperado dos sintomas constatados na avaliação anterior.

A altura de plantas refletiu a queima da área foliar. Na avaliação realizada aos 10 DAT, as plantas tratadas com carfentrazone-ethyl apresentavam redução média de sua altura em $25 \%$ em relação às plantas não tratadas (Tabela 3), sendo esse efeito também significativamente maior nas plantas que não receberam irrigação $(P=0,03)$. No entanto, a paralisação do crescimento da cultura foi temporária e as plantas recuperaram o porte e aos 30 DAT não apresentaram diferenças em relação às plantas não tratadas e também, não ocorreram diferenças entre plantas que receberam e as que não receberam irrigação, mesmo na testemunha (não capinada).

Tabela 3. Efeito dos tratamentos na altura de plantas de soja (em $\mathrm{cm})$. Passo Fundo, RS, $2001 / 2002$.

\begin{tabular}{|c|c|c|c|c|c|}
\hline \multirow[b]{2}{*}{ Nome técnico } & \multirow{2}{*}{$\begin{array}{c}\text { Ingrediente } \\
\text { Ativo } \\
\text { (g /ha) }\end{array}$} & \multicolumn{2}{|c|}{10 DAT } & \multicolumn{2}{|c|}{30 DAT } \\
\hline & & Não irrigado & Irrigado & $\begin{array}{c}\text { Não } \\
\text { irrigado }\end{array}$ & Irrigado \\
\hline Testemunha & - & $32,0 \mathrm{a}$ & $33,7 \mathrm{a}$ & $71,5 \mathrm{a}$ & $70,5 \mathrm{a}$ \\
\hline Testemunha capinada & - & $32,7 \mathrm{a}$ & $35,0 \mathrm{a}$ & $65,7 \mathrm{a}$ & $70,0 \mathrm{a}$ \\
\hline Carfentrazone-ethyl & 10 & $22,7 \mathrm{~b}$ & $26,0 \mathrm{~b}$ & $65,2 \mathrm{a}$ & 70,7 a \\
\hline $\begin{array}{l}\text { Carfentrazone-ethyl }+ \\
\text { imazethapyr }\end{array}$ & $10+24,5$ & $23,3 \mathrm{~b}$ & 24,7 b & $67,2 \mathrm{a}$ & $70,0 \mathrm{a}$ \\
\hline C. V (\%) & & 5,0 & 6,1 & 4,4 & 2,1 \\
\hline
\end{tabular}

A produção de matéria seca de soja (Tabela 4), determinada na floração, não foi 
afetada pelos tratamentos provavelmente devido ao rápido crescimento das plantas de soja e recuperação das plantas de soja em todos os tratamentos estudados, mesmo na testemunha (não capinada), o que foi, neste caso, atribuído à baixa competitividade de $E$. heterophylla infectadas por Bipolaris sp.

Tabela 4. Efeito dos tratamentos na produção de matéria seca de plantas de soja. Passo Fundo, RS, 2001/2002.

\begin{tabular}{lccc}
\hline \multirow{2}{*}{ Nome técnico } & \multicolumn{2}{c}{$\begin{array}{c}\text { Ingrediente } \\
\text { Ativo } \\
(\mathrm{g} / \mathrm{ha})\end{array}$} & \multicolumn{2}{c}{ Matéria seca $(\mathrm{Kg} / \mathrm{ha})$} \\
\cline { 3 - 4 } & - & $\begin{array}{c}\text { Não } \\
\text { irrigado }\end{array}$ & Irrigado \\
\hline Testemunha & - & $8.716 \mathrm{a}$ & $7.767 \mathrm{a}$ \\
Testemunha capinada & 10 & $8.864 \mathrm{a}$ & $7.540 \mathrm{a}$ \\
Carfentrazone-ethyl & $10+24,5$ & $7.958 \mathrm{a}$ & $7.795 \mathrm{a}$ \\
Carfentrazone-ethyl + imazethapyr & & $8.437 \mathrm{a}$ & $8.921 \mathrm{a}$ \\
C. V $(\%)$ & & 14,0 & 15,5 \\
\hline
\end{tabular}

Valores seguidos pela mesma letra, na coluna, não diferem entre si pelo teste de Duncan, ao nível de probabilidade de erro de $5 \%$.

Como o rendimento de grãos depende, também, da translocação de assimilados de folhas ou de outros órgãos fotossintetizantes (Hay \& Walker, 1992), ela poderia ter sido influenciada pela queima de folhas causadas pelos tratamentos. No entanto, não foram observados efeitos significativos dos tratamentos na produtividade de grãos (Tabela 5), provavelmente como conseqüência da recuperação das plantas de soja e da baixa competitividade de E. heterophylla infectada por Bipolaris sp.

Tabela 5. Efeito dos tratamentos no rendimento de grãos de soja. Passo Fundo, RS, $2001 / 2002$.

\begin{tabular}{|c|c|c|c|}
\hline \multirow{2}{*}{ Nome técnico } & \multirow{2}{*}{$\begin{array}{c}\text { Ingrediente } \\
\text { Ativo } \\
\text { (g /ha) }\end{array}$} & \multicolumn{2}{|c|}{$\begin{array}{l}\text { Produção de grãos } \\
\text { (Kg/ha) }\end{array}$} \\
\hline & & $\begin{array}{c}\text { Não } \\
\text { irrigado }\end{array}$ & Irrigado \\
\hline Testemunha & - & 2.773 & 2.797 \\
\hline Testemunha capinada & - & 2.822 & 2.877 \\
\hline Carfentrazone-ethyl & 10 & 2.727 & 2.840 \\
\hline Carfentrazone-ethyl + imazethapyr & $10+24,5$ & 2.616 & 2.777 \\
\hline C. V $(\%)$ & & 5,8 & 5,9 \\
\hline
\end{tabular}

Valores seguidos pela mesma letra, na coluna, não diferem entre si pelo teste de Duncan, ao nível de probabilidade de erro de $5 \%$.

O déficit hídrico no solo e, por inferência, na planta, influenciou o controle de Euphorbia heterophylla por carfentrazone-ethyl. A eficiência no controle da planta daninha foi maior $(P=0,0001)$ nos tratamentos que receberam irrigação, ou seja, quando as plantas não se encontravam sob estresse hídrico (Tabela 6).

Tabela 6. Controle de Euphorbia heterophylla L., em porcentagem Embrapa Trigo, Passo 
Fundo, RS, 2001/2002.

\begin{tabular}{|c|c|c|c|c|c|c|c|}
\hline \multirow[b]{2}{*}{ Nome Técnico } & \multirow{2}{*}{$\begin{array}{c}\text { (g ou } \\
\text { kg i.a./ } \\
\text { ha) }\end{array}$} & \multicolumn{2}{|c|}{$5 \mathrm{DAT}$} & \multicolumn{2}{|c|}{$21 \mathrm{DAT}$} & \multicolumn{2}{|c|}{35 DAT } \\
\hline & & $\begin{array}{c}\text { Não } \\
\text { Irrigado }\end{array}$ & Irrigado & $\begin{array}{c}\text { Não } \\
\text { Irrigado }\end{array}$ & Irrigado & $\begin{array}{c}\text { Não } \\
\text { Irrigado }\end{array}$ & Irrigado \\
\hline Testemunha & - & 0 & $0 \mathrm{~d}$ & $0 \mathrm{~d}$ & $0 \mathrm{c}$ & $0 \mathrm{c}$ & $0 \mathrm{c}$ \\
\hline $\begin{array}{l}\text { Testemunha } \\
\text { capinada }\end{array}$ & - & $100 \mathrm{a}$ & $100 \mathrm{a}$ & $100 \mathrm{a}$ & $100 \mathrm{a}$ & $100 \mathrm{a}$ & $100 \mathrm{a}$ \\
\hline Carfentrazone-ethyl & 10 & $50,0 \mathrm{c}$ & $71,7 \mathrm{c}$ & $78,3 \mathrm{c}$ & 91,7 b & $76,7 \mathrm{~b}$ & $91,7 \mathrm{~b}$ \\
\hline $\begin{array}{l}\text { Carfentrazone-ethyl } \\
+ \text { imazethabyr }\end{array}$ & $\begin{array}{l}10+ \\
245\end{array}$ & 76,7 b & $85 b$ & 83,3 b & 97,7 a & $80 \mathrm{~b}$ & $100 \mathrm{a}$ \\
\hline C. V $(\%)$ & & 5,1 & 2,2 & 3,4 & 2,3 & 4.4 & 2,0 \\
\hline
\end{tabular}

Valores seguidos pela mesma letra, na coluna, não diferem entre si pelo teste de Duncan, ao nível de probabilidade de erro de $5 \%$.

A mistura de carfentrazone-ethyl com imazethapyr apresentou melhor controle da planta daninha em relação à aplicação isolada do produto, em qualquer dos regimes hídricos estudados, em todas as avaliações. Possivelmente, a combinação da ação rápida de contato das aril triazolinonas, dessecando a planta, com a ação sistêmica de imazethapyr, atingindo pontos de crescimentos e/ou órgãos subterrâneos da planta daninha, foi a causa do melhor controle da espécie.

A susceptibilidade de plantas a herbicidas é, muitas vezes, alterada por estresses que afetam a capacidade das plantas em metabolizar esses produtos, influenciando tanto a fitotoxicidade à cultura como o controle de Euphorbia heterophylla. Plantas sob estresse hídrico apresentam menores taxas de crescimento e podem produzir menores quantidades de clorofila (Botha \& Botha, 1979). Dessa forma, reduzem a produção de protoporfirina IX no citoplasma, reduzindo, assim, a produção de singletos de oxigênio e, assim, a destruição de membranas celulares (Botha \& Botha, 1979). Essas plantas podem, também, ter elevados níveis de dismutase do superóxido (Zang \& Kirkham, 1994), possibilitando a detoxificação dos singletos de oxigênio, reduzindo também assim, a atividade de herbicidas cujo mecanismo de ação é a inibição da protox.

A influência de fatores de ambiente na atividade de herbicidas relaciona-se, também, à mudanças morfológicas impostas às plantas pelo ambiente. Plantas em estresse hídrico podem ter cutículas desidratadas que podem reduzir a absorção de carfentrazone-ethyl, resultando, assim, em menor grau de fitotoxicidade à cultura e menor eficiência do produto no controle da planta daninha (Peregory et al. 1990).

Por fim, os resultados permitem afirmar que: o status hídrico do solo, antes da aplicação dos tratamentos, influenciou o efeito de carfentrazone-ethyl, aplicado isoladamente ou em mistura com imazethapyr, tanto na seletividade do produto à soja como na sua eficiência no controle de E. Heterophylla. Que os sintomas fitotóxicos dos tratamentos com carfentrazone-ethyl foram maiores quando o produto foi aplicado sobre as plantas de soja que não estavam sob estresse hídrico. Que o melhor controle de $E$. heterophylla foi obtido quando o produto foi aplicado sobre plantas que não estavam sob estresse hídrico. Que a adição de imazethapyr ao carfentrazone-ethyl melhorou o controle da planta daninha e que, as plantas de soja recuperaram-se da fitotoxicidade inicial causada pelos tratamentos com carfentrazone-ethyl e não houve efeito sobre a altura final de plantas e nem na produtividade de biomassa e de grãos.

\section{LITERATURA CITADA}


ADKINS, S.W.; TANPIPAT, S.; SWARBRICK, J.T; BOERSMA, M. Influence of environmental factors on glyphosate efficacy when applied to Avena fatua or Urochloa panicoides. Weed Research, v.38, p.129-138, 1998.

ASHTON, F.M.; CRAFTS, A.S. Mode of action of herbicides. 2 ed. New York: John Wiley, 1981. 525p.

BASAIK, R.; RANA, D., ACHARYA, P.B.B. Alterations in the activities of active oxygen scavenging enzymes of wheat leaves subjected to water stress. Plant and Cell Physiology, v.35, n.3, p.489-495, 1994.

BOTHA, F.C.; BOTHA, P.J. The effect of water stress on the nitrogen metabolism of two maize lines. II. Effects on the rate of protein synthesis and chlorophyll II content.

Physiology and Biochemistry of Field Crops, v.1, n.2, p.179-183, 1979.

DAYAN, F.E.; DUKE, S.O.; WEETE, J.D.; HANCOCK, H.G. Selectivity and mode of action of carfentrazone-ethyl, a novel phenyl triazolinone herbicide. Pesticide Science, v.51, p.65-73, 1997.

DEVINE, M. D.; DUKE, S. O.; FEDTKE, C. Oxygen toxicity and herbicidal action. In: DEVINE, M. D.; DUKE, S. O.; FEDTKE, C., ed. Physiology of herbicide action. Englewood Cliffs, NJ: Prentice Hall, 1993. p. 277-288.

FMC. Aurora 400 CE. Campinas, [2001]. 14p.

GRESSEL, J. \& SEGEL, L. A. 1990. Modeling the effectiveness of herbicide rotations and mixtures as strategies to delay or preclude resistance. Weed Technology, 4: 186-198.

HARRISON, M.A.; HAYES, M.R.; MULLER, T.C. Environment affects cotton and velvetleaf response to pyrithiobac. Weed Science, v.44, p.241-247, 1996.

HAY, R. K. M.; WALKER, A . J. An introduction to the physiology of crop yield. New York: Longman Scientific \& Technical. 292 p.

HINZ, J.R.R.; OWEN, M.D.K. Acetolactate synthase resistance in a common waterhemp (Amaranthus rudis) population. Weed Technology, v.11, p.13-18, 1997.

JEFFCOAT, B.; HARRIES, B.N.; THOMAS, D.B. Factors favouring the choice of flamprotmethyl $( \pm)-2-((\mathrm{N}-(3-$ choro-4-fluorophenyl)benzamido) propionate for the control of Avena species in wheat. Pesticide Science, v.8, p.1-12, 1977.

LICH, J.M.; RENNER, K.A.; PENNER, D. Interaction of glyphosate with postemergence soybean (Glycine max) herbicides. Weed Science, v.45, p.12-21, 1997.

PEREGORY, R.S.; KITCHEN, L.M.; JORDAN, P.W.; GRIFFIN, H. Moisture stress effects on the absorption, translocation, and metabolism of haloxyfop in johnsongrass (Sorghum halepense) and large crabgrass (Digitaria sanguinalis). Weed Science, v.38, p.331-337, 1990.

REUNIÃO DE PESQUISA DE SOJA DA REGIÃO SUL, 22., Cruz Alta, 1994.

Recomendações técnicas para a cultura da soja no Rio Grande do Sul e Santa 
Catarina 1994/95. Cruz Alta: Fundacep, 1994. 66p.

RITTER, R.L.; COBLE, H.D. Influence of temperature and relative humidity on the activity of acifluorfen. Weed Science, v.29, p.480-485, 1981.

RODRIGUES, B.N. Guia de herbicidas. 3 ed. Londrina: Ed. dos Autores, 1995. 675p.

SCHABENBERGER, O. Slicing interactions in SAS. Disponível em:

<http://www.stat.vt.edu/oliver/SASSlice.htm> Acesso em: 6 jul. 2001.

SHERMAN, T.D.; BECERRIL, J.M.; MATSUMOTO, H.; DUKE, M.V.; JACOBS, J.M.; JACOBS, N.J. DUKE, S.O. Physiological basis for differential sensitivities of plant species to protoporphyrinogen oxidase inhibiting herbicides. Plant Physiology, v.97, p.280-287, 1991.

ZANG, J.; KIRKHAM, M.B. Drought-stress-induced changes in activities of superoxides dismutase, catalase, and superoxidase in wheat species. Plant and Cell Physiology, v.35, n.5, p.785-791, 1994. 